\title{
Assessment of consumer knowledge towards fortified foods
}

\author{
Bhavya Pande and Sarla Lakhawat
}

Received: 29.08.2019; Revised: 19.10.2019; Accepted: 03.11.2019

See end of the paper for authors' affiliations Bhavya Pande

Department of Food Science and Nutrition, College of Community and Applied Science, Maharana Pratap University of Agriculture and Technology, Udaipur (Rajasthan) India Email : bhavyapande@ymail. com
ABSTRACT : A study was planned to assess consumer knowledge towards fortified foods. A total of 150 female consumers age 25 and above residing in the Udaipur city were chosen. Various aspects of knowledge were assessed using a self-developed questionnaire. The scoring of questions was done on a two-point continuum i.e., correct or incorrect. Each correct response was awarded a score of one and incorrect a zero. ANOVA was used to compare consumer knowledge among different age groups and education qualifications. Results revealed that overall knowledge regarding fortified foods was poor (52\%), followed by 36 per cent had average knowledge, whereas only 12 per cent had high knowledge score. About 51.33 per cent of consumers were aware of the term food fortification. There was a significant difference in knowledge scores between different age groups ( $\mathrm{p}<0.01)$ namely, group I (25-36), group II (37-48), and group III (4960). Similarly, a large margin was also seen between educational qualifications of the consumers ( $\mathrm{p}<0.01)$. Thus, the overall knowledge of fortified foods was reported to be poor.

KEY WORDS: Knowledge, Fortified foods, Micronutrients, Hidden hunger

- HOW TO CITE THIS PAPER : Pande, Bhavya and Lakhawat, Sarla (2019). Assessment of consumer knowledge towards fortified foods. Asian J. Home Sci., 14 (2) : 347-353, DOI: 10.15740/HAS/AJHS/14.2/ 347-353. Copyright@ 2019: Hind Agri-Horticultural Society. 